\title{
LA CASA GRANDE O EL ETERNO RETORNO DEL ODIO Y LA VIOLENCIA UNA LECTURA EN CLAVE DE MEMORIA ${ }^{1}$
}

\author{
LA CASA GRANDE OR THE \\ ETERNAL RETURN OF HATRED \\ AND VIOLENCE, A READING IN \\ KEY OF MEMORY
}

\author{
LA CASA GRANDE OU O ETERNO \\ RETORNO DO ÓDIO E A \\ VIOLÊNCIA, UMA LEITURA EM \\ TERMOS DE MEMÓRIA
}

Por:

\section{Laura Sofía Fontal G.}

Profesora

Universidad del Valle, Sede Palmira

180 laura.fontal@correounivalle.edu.co

Resumen: El presente artículo tiene por objeto realizar una lectura de la novela $\mathrm{La}$ casa grande (1962) del autor Álvaro Cepeda Samudio desde algunas categorías de la memoria social. Se rastrea la aparición de tres tipos de memoria en el cuerpo de la novela, una memoria individual y autobiográfica, una memoria histórica referente a la masacre de las bananeras de 1928 y una memoria mítica del complejo nacional.

La función de la literatura en la construcción de sentido acerca del pasado de la nación se pone en diálogo con la labor histórica, y se privilegia su aporte en tanto producción cultural.

Palabras clave: Memoria social, La casa grande, Álvaro Cepeda Samudio, Mito del eterno retorno, Violencia en Colombia. 
Abstract: This article attempts to get a reading of the novel La casa grande (1962) of the author Álvaro Cepeda Samudio, from some categories of the social memory. In order to achieve this, is searched the appearance of three types of memory in the body of the novel, which are an individual and autobiography memory, a historical memory related with the Banana massacre in 1928 and finally, with a mythical memory that underlie the national complex.

The function of literature in the construction of sense about the past of the nation it is set on a discussion with the historic labor and is privileged its contribution as a cultural production.

Key Words: Social memory, La casa grande, Álvaro Cepeda Samudio, Myth of the eternal return, Violence in Colombia.

Resumo: Este artigo tem como objetivo realizar uma leitura do romance La casa grande (1962) do escritor Álvaro Cepeda Samudio a partir de algumas categorias da memória social. Rastreja-se a aparição de três tipos de memória no corpo do romance: uma memória individual e autobiográfica, uma memória histórica concernente ao massacre das bananeiras de 1928 e uma memória mítica do complexo nacional. A função da literatura na construção do sentido do passado da nação dialoga com o labor histórico, e privilegia-se seu aporte como produção cultural.

Palavras-chave: Memória social, La casa grande, Álvaro Cepeda Samudio, mito do eterno retorno, violência na Colômbia.

\section{Introducción}

La casa grande (1962) es la única novela publicada del autor Álvaro Cepeda Samudio. Apareció a comienzos de la década de 1960 en medio de las renovaciones estilísticas que sugería el "Grupo de Barranquilla" con una propuesta poco convencional de narración.

La novela da cuenta de un drama familiar que se desarrolla de manera paralela a los acontecimientos de la huelga y masacre de las bananeras, que tuvo lugar en Ciénaga, Magdalena, en diciembre de 1928. Las reconstrucciones historiográficas al respecto han establecido que la masacre fue perpetrada por el ejército nacional para reprimir a los huelguistas. Las tropas abrieron fuego por orden del general Cortés Vargas, Jefe Civil y Militar de Santa Marta, contra una multitud que agrupaba huelguistas, mujeres y niños asociados al enclave bananero establecido por la United Fruit Company, compañía frutera de origen estadunidense. El número de muertos continúa siendo una incógnita, lo que contribuye a la impunidad del hecho. Algunas fuentes mencionan trece muertos, mientras en otras la cifra se eleva a cientos o miles. 
Debido a que la novela de Cepeda Samudio ofrece una versión de estos acontecimientos, algunos autores como Urdinola (2004) la catalogan como "una novela de registro histórico"; sin embargo, debido a que no comunica una única versión del hecho y a que rehúye a dar una versión sólida y concisa de lo sucedido, se considera que la novela toma partido por la memoria más que por la historia. Al respecto, García Márquez en el prólogo de 1967 señala que la estructura fragmentada y dispersa que maneja la obra se parece a la de los recuerdos.

Más de treinta años después, el acontecimiento de la masacre de las bananeras reapareció elaborado en varias construcciones literarias y teatrales, no solo en La casa grande. Probablemente, el abordaje que le dio la novela Cien años de soledad ha sido el más memorable ${ }^{2}$.

Rescatado del olvido histórico al que parecía condenado, el evento de la masacre fue reelaborado en una mezcla de ficción y realidad que cuestionó la función histórica de la literatura y su capacidad de reconstruir el pasado de Colombia.

En el presente artículo se reconoce el debate con la historia; sin embargo, se introduce la categoría de memoria como la más apropiada para caracterizar la función que realiza la obra seleccionada en la reelaboración de acontecimientos históricos. La casa grande se considera entonces como una construcción de memoria acerca de los eventos de la huelga y la masacre de las bananeras. Siguiendo los planteamientos de Erll (2012), las obras literarias se consideran como reelaboraciones de memorias y mentalidades preexistentes en la colectividad, que contribuyen a la renovación de la memoria colectiva siempre y cuando los lectores las identifiquen y les atribuyan una relación con la realidad.

Además, se tratará de demostrar que en la novela está plasmada una memoria mítica acerca del pasado colombiano, memoria que supera los límites espacio-temporales de los sucesos de las bananeras. La memoria que reproduce acerca del complejo nacional da cuenta de la precaria elaboración de los acontecimientos de violencia sucedidos a lo largo de la historia de Colombia.

El resultado de este ejercicio se presenta como una actualización de la lectura de la novela seleccionada en clave de memoria, que rescata relatos del olvido histórico y revela construcciones sociales narrativas acerca de la realidad colombiana que han circulado desde la segunda mitad del siglo XX. De manera transversal a todo el artículo, se pone la cuestión de si la actividad literaria tiene un carácter funcional en la construcción de memorias que se vinculan en el acto de dotar de sentido la realidad nacional. 


\section{Acerca de La casa grande}

La casa grande se divide en nueve capítulos titulados con nombres de personajes y algunos días de la semana. Encontramos entonces "Los soldados", "La hermana", "El padre”, "El pueblo”, “Jueves”, “Viernes”, “Sábado”, “El hermano” y “Los hijos”.

El lugar central del relato es la casa grande, un espacio sustentado por la dinámica familiar. Este espacio imaginario supera los límites del recinto doméstico y se convierte en una metáfora de varios lugares, la casa grande es el espacio familiar, al mismo tiempo el pueblo, la zona bananera y la nación. Para Sims, "la casa grande es a la vez el recinto familiar y la nación que han sido sacudidos por la violencia” (1998, p.83).

La novela realiza un registro de los sucesos de la huelga y la masacre ocurridos en "la zona”, como se refiere a la zona bananera. Los acontecimientos no se presentan de manera cronológica ni lineal, aparecen de manera dispersa a lo largo de los capítulos. Esto produce giros en el relato, alternación entre los hechos presentados de la huelga y de la situación intrafamiliar y variedad de elipsis.

El lenguaje literario se caracteriza por ser bastante innovador, casi experimental, con predominancia de diálogos y monólogos que remiten a reflexiones interiores de los personajes. Este estilo de escritura recuerda el utilizado por otro autor del "Grupo de Barranquilla”, Gabriel García Márquez, en su obra La hojarasca y, de igual manera, remite a la narrativa del norteamericano William Faulkner³ .

En el libro, "el autor representa el acontecimiento (de la masacre de las bananeras) al desprenderlo del discurso histórico" (Sims, 1998, p.78). El cómo de la masacre aparece desde distintas perspectivas y voces, contrario al discurso monológico propio de la historia; por lo tanto, no se establece una única versión integral y sólida de lo acontecido. El hecho de la masacre se deduce al ser presentada tanto por los soldados, como por la familia, el pueblo y la versión oficial. Cada complejo de personajes presenta una perspectiva distinta de los acontecimientos en medio de un gran discurso polifónico.

Entre el capítulo cuarto y el quinto, justo antes de los días de la semana, se introduce una sección que se denomina "El decreto". No es un capítulo en sentido estricto; reproduce el decreto número 4 del Jefe Civil y Militar de la provincia de Santa Marta, documento histórico que da cuenta de los sucesos de la huelga y la masacre, con leves modificaciones del documento original.

El decreto se integra en la novela como si se tratase de un anexo, contribuye a un salto temporal que de manera tardía le comunica al lector el lugar, la fecha y las condiciones de la huelga y la masacre que se han relatado en los capítulos anteriores de manera incompleta. Con el decreto se le otorgan coordenadas específicas a los eventos narrados y se acentúa aún más el contexto espaciotemporal e ideológico de la novela. 


\section{La memoria social, una tipología}

La teoría de la memoria dentro de las ciencias sociales ha tenido un amplio desarrollo, sobre todo en los debate de la postguerra. En la segunda mitad del siglo $\mathrm{XX}$, países como Alemania y Estados Unidos apoyaron iniciativas de recuperación de memoria para dar voz a las víctimas y evitar el olvido de los acontecimientos pasados, aun si tenían una gran carga de traumatismo. Desde entonces, la función social de la memoria ha estado vinculada a los contextos de transición y postconflicto en los que se hace urgente dotar de sentido lo acontecido para trascender a una nueva etapa.

No obstante, la aplicabilidad de la memoria social no se restringe a los procesos de postguerra. Se identifica la memoria en los esfuerzos sociales o individuales por construir sentidos sobre el pasado, por lo que se puede rastrear en amplios y diversos campos.

Los trabajos de memoria se pueden realizar de manera paralela a la construcción de la historia, pero no la sustituyen ni cumplen la misma función. Uno pertenece al campo del análisis histórico, mientras que las memorias pertenecen al de la interpretación cultural (Rodríguez, 2008).

Pécaut establece una tipología de relatos para distinguir entre aquellos que logran ser integrados y con miras al futuro y aquellos que reproducen la memoria. Por un lado señala al relato histórico, que se caracteriza por realizar una reconstrucción objetiva de los acontecimientos, se basa en la periodización, depende de criterios de verificación y pretende ser unificado. La historiografía como disciplina ligada al quehacer académico es productora de este tipo de relatos porque apela a los mismos criterios de objetividad y validez. Por otro lado se encuentran las memorias que son múltiples, remiten a la temporalidad vivida, no implican una periodización definida y van ligadas a la experiencia individual o colectiva (Pécaut, 2013a). La voz desde la que se construye la memoria puede ser subjetiva, mientras que la voz de la historia es la objetividad.

La memoria, entonces, no es la recuperación fiel de lo acontecido. Se trata de una selección de contenidos para hacer una reelaboración y reinterpretación del pasado según las necesidades del presente; por eso en las memorias el pasado puede ser tergiversado, puesto en duda, olvidado y renarrado muchas veces. Al respecto, Pécaut menciona "la memoria se reinventa a medida que se modifican las realidades. Toda memoria es memoria a partir del presente.” (2013a, p.183)

La memoria se rastrea en diversas manifestaciones discursivas que comunican las experiencias vividas, por eso se define como una "construcción social narrativa" (Rodríguez, 2008) que compromete significados y sentidos, y transmite las representaciones de quienes las producen. Se pueden encontrar memorias en forma de relatos escritos, tradición oral, mitos, monumentos, entre otros. 
Debido a que las memorias surgen de narraciones compartidas se considera que a toda sociedad subyace un entramado de memorias colectivas. Toda memoria tiene un carácter social; sin importar lo íntima o personal que pueda parecer requiere una mediación lingüística y narrativa para ser comunicada (Rodríguez, 2008).

\section{La memoria individual}

Halbwachs señala que los individuos participan de dos tipos de memoria, una individual y una colectiva. La primera es una memoria personal, interior, autobiográfica que "puede respaldarse en la memoria colectiva, situarse en ella y confundirse momentáneamente con ella para confirmar determinados recuerdos" (Halbwachs, 2004, p.54). Por otra parte, la memoria colectiva es exterior, social e histórica, más amplia que la memoria individual. Para este autor, la memoria colectiva envuelve las memorias individuales pero no se confunde con ellas.

El individuo obtiene recuerdos de su propia experiencia y de la memoria exterior para agregarlos a su memoria individual. En algunos casos, a sus recuerdos reales se añaden recuerdos ficticios obtenidos de testimonios que otras personas le heredan.

Toda memoria individual está condicionada por contextos sociales de producción. El análisis de los grupos de pertenencia cobra vigencia en este sentido para entender los entramados sociales y culturales que sirven como marcos de producción de las memorias. Al respecto, Halbwachs (2004) señala que lo que permite que un recuerdo se active es que forma parte de un conjunto de pensamientos comunes a un grupo de pertenencia, es por identificación con el grupo que el individuo asumen intereses y orienta sus reflexiones.

\section{Memoria histórica}

La memoria histórica constituye "la serie de hechos cuyo recuerdo conserva la historia nacional” (Halbwachs, 2004, p.79), es la memoria escrita o la memoria documentada que queda para el gran grupo de la nación. Un individuo no puede identificar su propia vida en ese relato inmenso de acontecimientos que seguramente no vivió pero que reconoce gracias a recuerdos que otros le han compartido. La memoria histórica es esa memoria exterior, que excluye el universo de lo íntimo.

Los eventos consignados en esta memoria son indicadores de procesos reconocidos de la historia nacional, sirven como contexto a otros relatos extraídos de la memoria individual o de memorias colectivas. El grupo nacional ha sido marcado por determinados hechos que componen la memoria de la nación, el individuo que no los ha vivido puede evocarlos gracias a que los ha copiado de otra memoria que no es la suya y que le ha sido transmitida por periódicos, libros o testimonios. Cada individuo posee un bagaje de recuerdos históricos que puede aumentar con conversaciones y lecturas (Halbwachs, 2004). 
Los acontecimientos históricos o nacionales que aparentemente son exteriores a las circunstancias de la existencia individual, permiten situarse a sí mismo en la historia de la época.

Si bien, la memoria histórica se conserva escrita a manera de textos que contienen la historiografía, también se agregan eventos que se conocen por otras formas como la oralidad. Para Halbwachs es importante el "vínculo vivo de las generaciones" como un mecanismo de transmisión de memorias, gracias a él se comparten no solo los hechos, sino también las formas de ser y de pensar de antaño (2004, p.66). En este sentido, la historia, entendida como sucesión cronológica de hechos y fechas estaría incompleta puesto que los libros y los relatos ofrecen una representación muy esquemática e incompleta de los periodos históricos.

La memoria histórica es el repertorio vivo de elementos que no quedan consignados en la historia, permite a los individuos referenciar hechos y eventos del pasado, basados en su experiencia o en la de la colectividad a la que pertenecen.

\section{Memoria mítica y repetición}

Los relatos históricos deben unificar y conjugar en una sola visión legítima las múltiples versiones sobre el pasado para crear una versión reconocida y compartida, que trascienda las memorias míticas. Este tipo de memorias se imponen como versiones reconocidas del pasado y dan lugar a representaciones vagas y confusas sobre lo sucedido.

Cuando no se elabora un relato histórico uniforme, por ejemplo para la historia de un país, no hay un soporte suficiente para los trabajos de la memoria; por lo tanto, lo que debería ser la historia se entremezcla con fragmentos de memoria y da lugar a una elaboración precaria del pasado, con muchos vacíos y contornos poco definidos. En esos casos, el relato que termina por divulgarse y legitimarse en el plano público corresponde a una "vulgata histórica" (Pécaut, 2013a). La vulgata se define por la indistinción entre la memoria y el relato histórico, es el punto medio entre memoria e historia que reproduce categorías míticas, propias de la memoria, y las añade a lo que debería ser el relato histórico, restándole coherencia y objetividad.

Las memorias míticas no remiten a circunstancias específicas ni a actores concretos, por lo que dificultan emitir juicios y superar los eventos traumáticos. Para Pécaut, en Colombia subsiste una representación mítica del tiempo en la que los acontecimientos de violencia carecen de referentes estables en el pasado y se inscriben en la larga duración de la repetición; por lo tanto, "la violencia de hoy no deja de ser vista como el regreso de la anterior, y sus formas, como idénticas a las que se habían dado" (2013b, p. 130). En consecuencia, distintas generaciones se han representado la historia del país como la historia de la violencia y, en particular, le atribuyen a la Violencia de los años cincuenta el origen de todas las formas de violencia posteriores. 


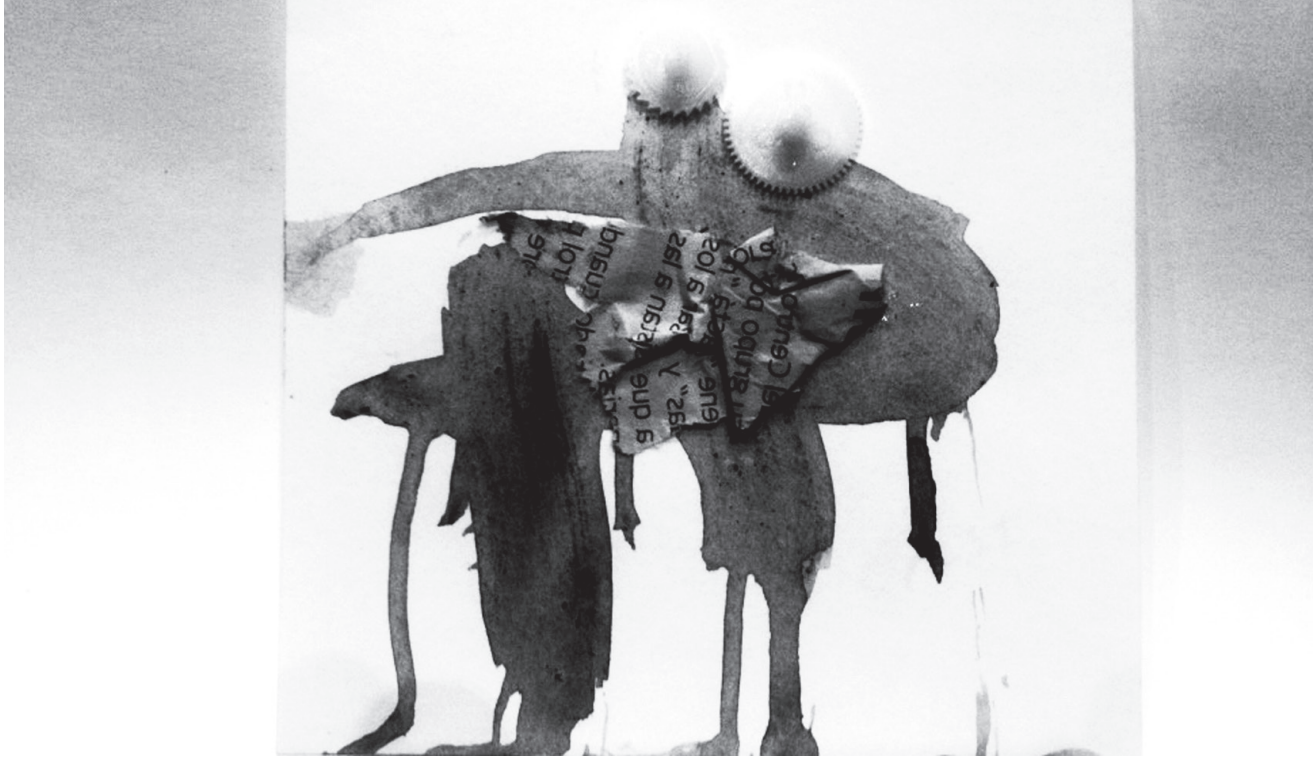

Esta representación de los fenómenos de violencia se origina de la imposibilidad de integrarlos en un relato que les confiera significado. Como señala el mismo autor, los esfuerzos de los historiadores por interpretar estos episodios son obstaculizados y desvalorizados por los políticos que prefieren cubrirlos con un manto de olvido. La consecuencia de ese conflicto de intereses es que la violencia o la catástrofe permanece por fuera de una historia enunciable y "siempre queda allí, tan terrible como una maldición dedicada a atormentar sin fin a las generaciones futuras" (Pécaut, 2013b, p. 132).

\section{La historiografía de la masacre de las bananeras}

En la década de 1960, cuando apareció la novela de Cepeda Samudio, aún no se había registrado de manera suficiente la masacre de las bananeras ni la huelga de los trabajadores. Las obra historiográfica que existía sobre el pasado colombiano en general se caracterizaba por la improvisación y los sesgos ideológicos, ya que era realizada por "un pequeño grupo de intelectuales que se ocupaban de esa disciplina a veces por tradiciones familiares y otros por conveniencia política o ideológica" (Friede, citado en Tirado, 2014, p. 260).

Para entonces, las fuentes de información sobre las bananeras se reducían al cubrimiento que hizo la prensa nacional en su momento y a algunos testimonios poco difundidos de líderes obreros como Raúl Eduardo Mahecha y Alberto Castrillón. También se habían dado a conocer las investigaciones de 1929 lideradas por Jorge Eliécer Gaitán ante el Congreso de la República y un libro con la versión “oficial” del general Cortés Vargas, pero ninguno de esos documentos logró un impacto apreciable en el escenario público.

Además, la versión que se impartía oficialmente en las escuelas y colegios del país correspondía a la de los manuales de enseñanza de la historia, como los de Rafael M. Granados, Jesús María Henao y Gerardo Arrubla, que se habían constituido en lecturas obligatorias. En esos textos, la historia nacional era un relato de victorias presentadas a través de la vida de héroes militares y de presidentes, convertidos en personalidades victoriosas y nobles. 
Los eventos de las bananeras eran retratados como un accionar legítimo de las tropas para hacer frente a la "insurrección comunista" que tomaba caracteres alarmantes, como se puede leer en la breve reseña contenida en el manual para cuarto año de bachillerato de Rafael M. Granados. En él, los huelguistas son denominados "revoltosos" y son señalados como uno más de los "peligrosos escollos" por los que el doctor Abadía - presidente de la república en ese entonces- tuvo que "conducir la nave del Estado" (Granados, 1972, p. 445).

Ya en la década de 1970, la renovación de la historiografía en manos de la denominada Nueva Historia permitió que el ejercicio fuera dotado de carácter académico y objetivo. Los intelectuales comenzaron a verificar el pasado nacional y a desentrañar versiones ocultas para construir nuevos relatos; fue entonces cuando aparecieron nuevas versiones sobre la masacre de las bananeras, contrarias a la versión oficial que había circulado hasta entonces.

Para algunos investigadores, fue el reconocimiento que tuvo Cien años de soledad lo que posibilitó que en los años setenta se abordara el pasado de las bananeras. El historiador Nicolás Pernett, por ejemplo, le atribuye al impacto masivo de la novela el hecho de que la masacre hubiera resurgido del olvido histórico en que se encontraba. Según él, fue a partir de la novela que la masacre "se empezó a hacer presente con más fuerza en la conciencia histórica y política nacional y en las varias investigaciones aparecidas de la década de 1970 en adelante" (Pernett, 2009, p. 194).

La precaria elaboración historiográfica se contempla como un factor por el que la literatura se apropió del pasado de las bananeras desde las voces fragmentadas de la memoria y así permitió que sobreviviera al olvido. Los relatos ficcionales contenidos en las novelas representaban las versiones no oficiales que aún no habían tenido difusión y que estaban a la espera de ser reveladas.

\section{Una lectura de La casa grande en clave de memoria}

Álvaro Cepeda Samudio nació en Barranquilla en 1926, dos años antes de la masacre de las bananeras. Aunque era muy pequeño para tener recuerdos de lo acontecido, creció en un entorno cargado de testimonios y marcado por el evento. En 1932 se trasladó a Ciénaga, el pueblo que fue epicentro de la masacre y que todavía la conservaba viva en el recuerdo. Estos hechos determinaron su obra, tal como se aprecia en La casa grande.

De acuerdo con la biografía de Bancelin (2012) sobre la vida del autor, "la represión de la huelga que escandalizó al país quedó plasmada en el recuerdo colectivo por generaciones y, gracias a la tradición oral, salió a relucir de nuevo cuarenta años después en La casa grande" (p.121).

La biógrafa da cuenta de cómo el autor, siendo un niño, permanecía en contacto con los chismes y comentarios que las amigas de su madre realizaban, conversaciones casi clandestinas acerca de la matanza que era innombrable en el escenario público. 


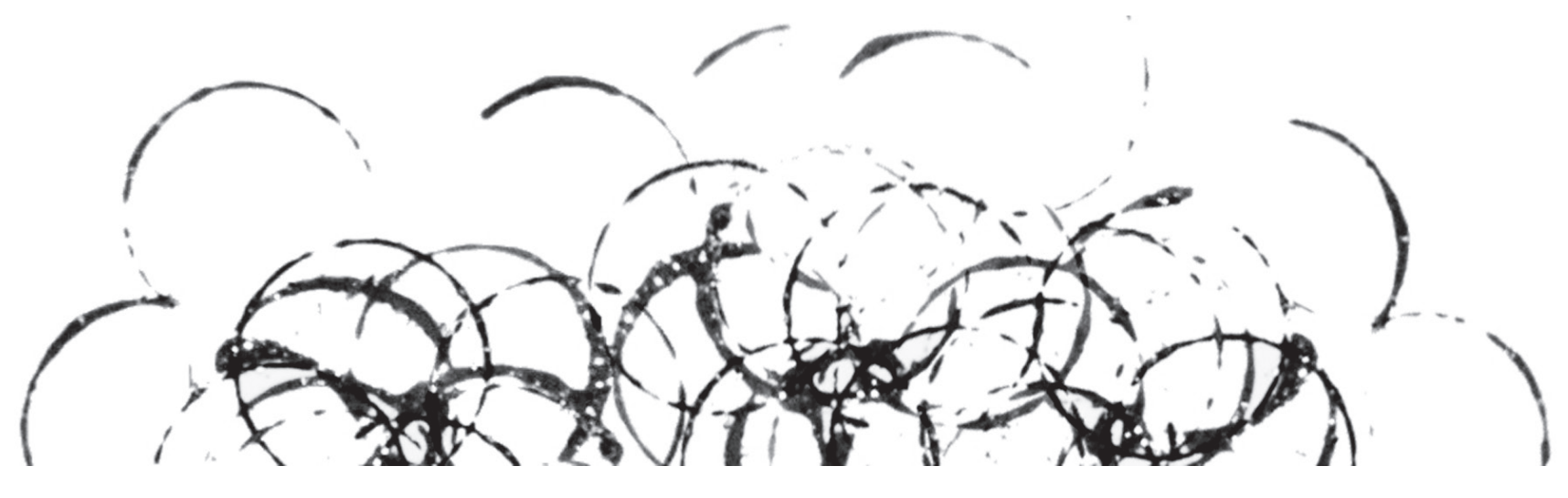

Elementos que entonces se conservaba en la memoria colectiva del pueblo y de la zona se instalaron en la memoria del individuo, que la conservó para años más adelante reelaborarla en forma de literatura.

Para su creación, Cepeda Samudio también utilizó personajes locales de su infancia, enfermedades que padeció, vivencias que tuvo y escenarios por los que paseó (Bancelin, 2012). El escenario literario fue construido a partir de objetos, lugares y personas conocidas. Bancelin conjetura acerca del personaje del Padre que, aparentemente, estuvo inspirado en un terrateniente bananero que hacía negocios con la United Fruit Company y era vecino del barrio del escritor. Según la biógrafa,

Otros personajes de la obra están inspirados en [...] cinco hermanos con los que Álvaro trabó amistad recién llegado a Ciénaga y que fueron sus vecinos [...]. Allá pasaba todo el día y regresaba de noche. A la mañana siguiente emprendía de nuevo el camino, no sin anunciar antes: 'Mami, me voy para la casa grande'(Bancelin, 2012, p.124).

Además, la casa de sus vecinos estaba ubicada al lado del cuartel militar que Cepeda conoció muy bien y que reproduce en su novela.

La huelga y la masacre de las bananeras en la novela aparecen contadas por variedad de personajes que comúnmente han sido silenciados por la historia y por las versiones oficiales. Estos personajes encarnan a los "no-sujetos" de la historia (Benavides, 2014).

La idea de los "no-sujetos" remite a las memorias marginales, aquellas que poseen los personajes que no han logrado ser voceros de su propio mundo, que encarnan valores y actitudes que no aparecen en la memoria histórica y mucho menos en la historia oficial.

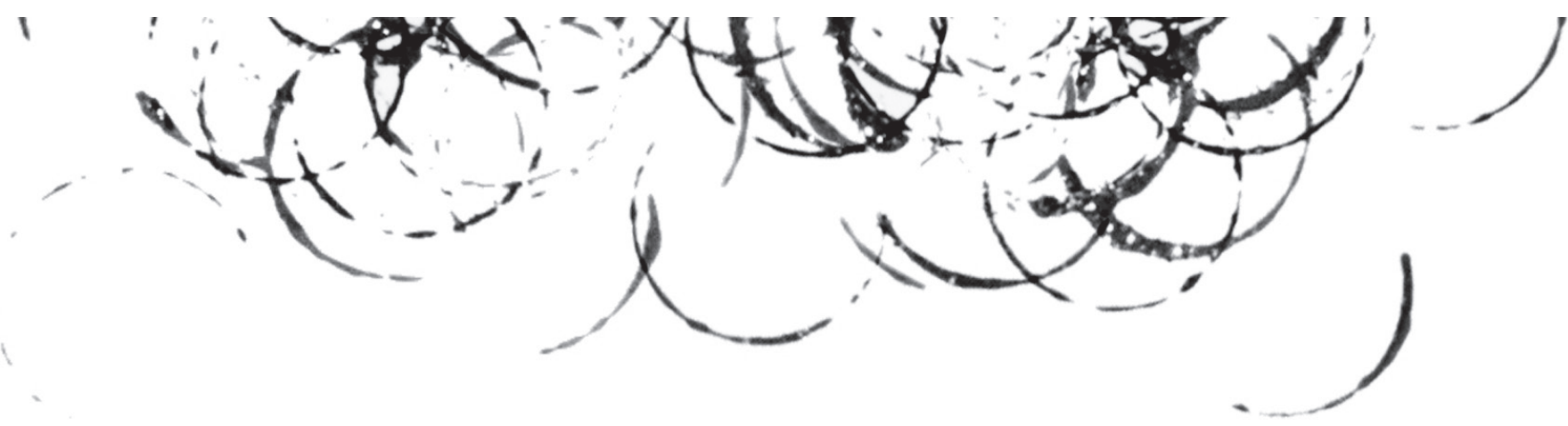


La novela construye y vehiculiza memorias acerca de la masacre a través de un relato ficcional que se aleja de la versión oficial e incluso la contradice. Para Vergara (2001), "en el fondo de la narración subyace la visión de un periodista empeñado en presentar un vox populi para desmentir la versión oficial de la masacre” (p.72), lo que da como resultado una vulgata histórica que, aunque se nutre del relato histórico y de las versiones oficiales, termina por subvertirlo dando primacía a los mecanismos de la memoria.

La aparición del decreto en medio de la obra contribuye al debate entre memoria e historia. Es un documento que sirve para contrastar el mundo del relato con el mundo por fuera de él. Para Sims, "el decreto representa la supuesta objetivación de la realidad y la voz monológica y autoritaria del mundo oficial" (1998, p.81), por eso es un "guiño" a la historia. Sin embargo, Cepeda realizó leves modificaciones al decreto original, por ejemplo cambió la fecha de la masacre, lo que dislocó el documento de su contexto original y lo separó de la cronología que mantienen los relatos acerca del acontecimiento (Sims, 1998). La manipulación de un documento para introducirlo en el mundo ficcional acentúa la oposición que la novela establece con respecto a la historia y a los relatos lineales que ella privilegia; el decreto es una disrupción más en el orden del relato. Con él se matiza la subjetividad que se ha sostenido hasta entonces, propia de los recuerdos y de las memorias y poco común en los relatos históricos, para confirmar y complementar datos que se han podido deducir de las voces de los personajes en los capítulos anteriores.

Otro elemento que refuerza el divorcio con la historia es la designación genérica de los personajes; no reciben nombres particulares, son denominados según el rol que cumplen dentro de la estructura familiar. Se reconocen los personajes que presentan los títulos de los capítulos, "la hermana", "el padre", "el hermano", "los hijos". "Los soldados" y "el pueblo" aparecen como unos personajes más dentro de los "sin rostro" que se designan de manera genérica. Por medio de este recurso, todos los personajes se vuelven ejemplificantes del mundo que se plantea. Sims señala además que los nombres genéricos ayudan a universalizar o mitologizar el hecho histórico (1998, p.79). La construcción arquetípica de los personajes lleva a una identificación casi universal que contribuye a "deshistorizar" los eventos narrados.

La presentación de monólogos que dan cuenta de distintas perspectivas y versiones de los sucesos relatados compone la polifonía que caracteriza a la novela. Este rasgo, además de la heterofonía o diversidad de voces individuales y la heterología o diversidad de discursos es lo que cataloga a la novela como "un género subversivo frente a la historia" (Sims, 1998). 
Según Brushwood, en La casa grande el hecho histórico se comunica "tal como ha quedado en la memoria, pero siempre en el contexto de pertenecer a una familia y a un pueblo" (citado en Sims, 1998, p.78). El autor evita narrar la masacre y opta porque sean los personajes quienes la presenten a través de selecciones provenientes de la memoria colectiva de la familia y del pueblo. La novela muestra los acontecimientos como algo que ya ha ocurrido en el pueblo y que los personajes pueden referenciar gracias a sus recuerdos, aunque la mayoría de ellos no los haya presenciado. El único testigo que se presenta es un soldado, su rememoración se remite exclusivamente a su experiencia y sólo habla de un muerto al que él asesinó (Cepeda, 2012, p.p.5860). Por esto el relato de la huelga y la masacre es parcial y fragmentado, al ser comunicado por varias voces no logra constituir un relato unificado como el de un narrador omnisciente, más cercano a lo que ocurre en los relatos históricos o en las reconstrucciones historiográficas.

A lo largo de los capítulos se van arrojando informaciones sobre el estado general de La Zona durante la huelga y la masacre. Algunos de esos detalles podrían parecer insignificantes, pero reconstruyen las minucias cotidianas de lo que sucedía por esos días. Por ejemplo, en el capítulo “jueves” hay un diálogo entre un hombre y una mujer que se encuentran en una cafetería, en él se menciona que no es posible salir del pueblo porque el tren no llegará (Cepeda, 2012, p.121). Es un detalle suelto que, sin embargo, da cuenta del ambiente del pueblo, aparentemente sosegado, pero que está pasando por eventos que lo conmocionan y que son consecuencias de la huelga. Al lector le corresponde armar las piezas para poder dar cuenta del hecho histórico y trazarlo como una sucesión ordenada ya que en la novela los acontecimientos van apareciendo dispersos en los distintos discursos, sin continuidad narrativa.

\section{La casa grande o el eterno retorno del odio y la violencia}

El relato de La casa grande está atravesado por el odio. Los personajes dan cuenta de él en sus monólogos y en sus diálogos como si se tratase de una realidad objetiva que todos conocen. El odio es una entidad que habita la zona, el pueblo y la casa; una entidad conocida por sus efectos perversos sobre la vida de los personajes, de la que no se puede escapar.

El odio, al igual que la violencia, proviene del interior y no de afuera como sucede por ejemplo en Cien años de soledad. La ausencia de personajes extranjeros y las escasas referencias a los Estados Unidos o a la compañía frutera resaltan como disonancia con la memoria histórica. Toda la violencia se circunscribe a lo doméstico, a lo íntimo y primario, ahí tiene su origen. El horror de la masacre se presenta como parte del hecho histórico pero luego se conecta con el drama familiar. Ambos complejos -la zona y el ámbito doméstico- están atravesados por el odio que tiene su origen en la figura de El Padre, un terrateniente poseedor de plantaciones de banano que al verse perjudicado por la huelga manifiesta su apoyo a los soldados y a la brutal represión. El Pueblo identifica al Padre como culpable de la tragedia y cobra venganza al asesinarlo. 
Sin embargo, el odio no muere con el Padre. La violencia patriarcal tiene su más fuerte eco en la familia: la madre, la hermana, el hermano. La violencia engendrada en el seno del hogar se vuelve contra ellos y, como un rasgo ligado a la sangre, se transmite de generación en generación. La Hermana y El Hermano encarnan la tragedia de quienes no pueden deshacerse del legado violento del progenitor. Posteriormente, Los Hijos también identificarán aquel "tejido inenarrable que agobia a la gente, a la familia, y del cual no se puede escapar” (Urdinola, 2004).

Imposibilitados de huir de la marca del odio, los personajes "son conducidos a su destino por un hado omnipotente, como ocurre en la tragedia griega” (Vergara, 2001, p.78). En un diálogo al final del libro, Los Hijos, que son la última generación de las tres que abarca la novela, manifiestan su derrota por la incapacidad que tienen de evadir el destino:

“-Es que si no hablamos ahora nos va a llenar el odio y entonces también estaremos derrotados.

-De todas maneras estamos derrotados.

-Sí: de todas maneras”. (Cepeda, 2012, p.165)

Los Hijos se debaten entre el odio destructivo y la posibilidad de liberarse de él, pero finalmente se reconocen como parte de un destino que se repite de manera inevitable. El presente y el porvenir no se pueden modificar pese a los intentos de los personajes, todas las generaciones son herederas del odio, la violencia y la injusticia. Han nacido condenados, derrotados de antemano.

La violencia se convierte en un elemento familiar no sólo por presentarse dentro del espacio doméstico e íntimo, sino porque se ha vuelto convencional y todos están familiarizados con ella.

La identificación de una fuerza que determina el destino sobre las voluntades individuales y de la que no hay escapatoria no es el único elemento que hace equiparable la narrativa a una tragedia griega. La repetición y el tiempo circular y cíclico también contribuyen a este efecto. De acuerdo con Vergara "el tiempo circular, cíclico, muestra el sentimiento de que la historia se repite” (2001, p.77).

$\mathrm{Al}$ equiparar el relato de la casa grande con el relato de Colombia se identifica la novela como una metáfora de un país que atenta contra sí mismo y que deposita un odio originario sobre su propia sangre. La violencia se genera en el seno de un "nosotros", vinculada a una identidad tan primaria como la que supone la filiación familiar; así, representa una violencia fratricida, donde el antagonismo con el enemigo es difuso.

La historia del complejo nacional representada en un relato en el que pasado, presente y futuro están atravesados por «la violencia», indisociables de la presencia de una entidad informe, tiene las características de una memoria mítica, una construcción social que retoma elementos del acontecer histórico y los tergiversa en un relato 
subjetivo, disperso, múltiple, sin coordenadas claramente identificables y, sobre todo, sin personajes concretos como responsables. El relato de Cepeda Samudio recuerda las palabras del sociólogo Fals Borda en su prólogo de 2005 al clásico estudio La violencia en Colombia, "[...] por periodos sucesivos, la violencia y el terror vuelven a levantar su horrible cabeza enmarañada de Medusa, como copia casi fiel de lo ocurrido antes; y ahora, al adentrarnos en el nuevo siglo, la tragedia tiende a repetirse paso a paso de manera irresponsable".

\section{Conclusiones}

En La casa grande se puede apreciar la reconstrucción de una memoria individual; la novela está inspirada en vivencias del autor, extraídas de su experiencia y del legado testimonial de su entorno. La aparición de personajes, lugares y experiencias de la infancia, por ejemplo, da cuenta de esto.

Por otro lado, sin desligarse por completo del entramado de la memoria individual, se encuentra la reelaboración de la memoria colectiva de las bananeras. Se establece un debate con la historia porque el autor privilegia los relatos subjetivos, personalizados, múltiples, similares a los relatos orales extraídos de la memoria colectiva del pueblo que le legó las primeras imágenes del acontecimiento.

El relato que ofrece acerca de la huelga y la masacre se aproxima a la memoria y se aleja del relato histórico básicamente por tres motivos: está relatado por multitud de voces y es polifónico, los personajes son enunciados con nombres genéricos y representan a todos aquellos que han vivenciado la violencia, no a ellos mismos como referentes particulares sino como referentes que se pueden universalizar. Y, finalmente, porque los acontecimientos no están anclados en una continuidad narrativa ni discursiva y no presentan coordenadas suficientes para un relato integrado. Los recuerdos de las bananeras fueron los soportes de la memoria histórica y de la vulgata que posteriormente permitieron que fuera rescatada del olvido histórico.

En ocasiones, la literatura participa en la construcción de relatos alternativos sobre el pasado que se enfrentan con las representaciones formales u oficiales, en esto consiste el conflicto que sostiene con la historia. El caso de la novela analizada es un claro ejemplo de cómo la literatura contribuye al campo de la memoria al recoger mentalidades colectivas y cómo puede rescatar versiones del pasado que aún no se han registrado en las versiones oficiales ni en las históricas. 
Los relatos recogidos en las obras literarias no son memorias en sí mismos, pero pueden abordarse como construcciones sociales narrativas cargadas de interpretaciones que los individuos o las colectividades hacen para dotar de sentido su realidad. Si la literatura se aborda como vehículo de la memoria es porque se concibe como producto cultural que contiene representaciones y sentidos sobre distintos sucesos que no son ajenos a contextos socioculturales específicos. Además, porque transmite representaciones propias de sujetos silenciados por los relatos oficiales y logra dar cabida en el escenario público a relatos que han sido marginados.

En su intento por dotar de sentido la realidad, las sociedades pueden crear mitos que pretenden llenar los vacíos de lo inenarrable. En su conjunto, la novela representa un mito del eterno retorno del odio y la violencia que también ha sido usado para dar cuenta de la historia de Colombia. Es una memoria-relato que pretende explicar el pasado de la nación apelando a la violencia como una entidad presente desde el origen de los tiempos, que se encarna en el destino de los personajes de manera trágica y de la que no se puede escapar. Ese mito ha estado presente en las mentalidades colectivas durante décadas e invita a pensar que, así como los últimos personajes de la novela, una sociedad que se cree condenada desde el inicio ya está derrotada.

\section{Notas}

\footnotetext{
${ }^{1}$ Este artículo tiene origen en los hallazgos de la tesis de pregrado de sociología Fontal, L. (2015). La reinvención del pasado. La masacre de las bananeras en la producción cultural de los años sesenta. Cali: Facultad de Ciencias Sociales y Económicas, Universidad del Valle.

${ }^{2}$ La autora ha rastreado 21 textos literarios y teatrales referidos al conflicto de las bananeras desde 1928 hasta 1996. La década de 1960 fue la más abundante en este tipo de producciones. Para consultar el listado completo, ver Fontal, Laura Sofía. (2015). La reinvención del pasado, la masacre de las bananeras en la producción cultural de los años sesenta. Tesis de pregrado de sociología. Cali: Facultad de Ciencias Sociales y Económicas, Universidad del Valle.

${ }^{3}$ La relación entre la obra de Faulkner y la de los escritores del denominado Boom latinoamericano (entre ellos Cepeda Samudio y García Márquez) se encuentra documentada. Como muestra, ver el estudio de Amparo Urdinola Uribe (2004), Faulkner en siete obras del Boom, editado por el programa editorial de la Universidad del Valle.Y el estudio de Joan Hernández (1978), The influence of William Faulkner in four latin american novelists, UMI Dissertation Information Center: Lousiana State University.
} 


\section{Referencias}

Bancelin, C. (2012). Vivir sin fórmulas, la vida intensa de Álvaro Cepeda Samudio. Bogotá: Editorial Planeta Colombiana, S.A.

Benavides, A. C. (2014). La soledad de Macondo o la salvación por la memoria. Bogotá: Siglo del Hombre Editores.

Cepeda Samudio, A. (2012). La casa grande. Bogotá: El Áncora Editores.

Erll, A. (2012). Memoria colectiva y culturas del recuerdo. Estudio introductorio. Bogotá: Universidad de los Andes, Facultad de Ciencias Sociales, Departamento de Lenguajes y Estudios socioculturales, Centro de Estudios Socioculturales e Internacionales; Ediciones Uniandes.

Fals Borda, O. (2005). Prólogo para la presente edición. En: O. Fals Borda, E. Umaña Luna \& G. Guzmán. (2010). La violencia en Colombia, Tomo I. Bogotá: Distribuidora y Editora Aguilar, Altea, Taurus, Alfaguara, S.A.

Fontal Gironza, L. S. (2015). La reinvención del pasado. La masacre de las bananeras en la producción cultural de los años sesenta. Tesis de pregrado de sociología. Cali: Facultad de Ciencias Sociales y Económicas, Universidad del Valle.

García Márquez, G. (1967). Prólogo, en: A. Cepeda Samudio. (2012). La casa grande. Bogotá: El Áncora Editores.

Granados, R. M. (1972). Historia de Colombia. La independencia y la República. Texto adaptado al cuarto año de bachillerato. Duodécima edición. Bogotá: Imprenta Patriótica del Instituto Caro y Cuervo.

Halbwachs, M. (2004). La memoria colectiva. Zaragoza: Prensas Universitarias de Zaragoza.

Pécaut, D. (2013a). Memoria imposible, historia imposible, olvido imposible. En: La experiencia de la violencia: los desafíos del relato y la memoria. Medellín: La carreta editores.

(2013b). Configuraciones del espacio, el tiempo y la subjetividad en un contexto de terror: el caso colombiano. En: La experiencia de la violencia: los desafíos del relato y la memoria. Medellín: La carreta editores.

Pernett, N. (2009). La masacre de las bananeras en la literatura colombiana. En: M. Archila \& L. J. Torres (editores). Bananeras: huelga y masacre 80 años. Bogotá: Universidad Nacional de Colombia. Facultad de Derecho, Ciencias Políticas y Sociales, Facultad de Ciencias Humanas, Grupo de Trabajo Realidad y Ficción.

Rodríguez Idárraga, N. (2008). Los vehículos de la memoria. Discursos morales durante la primera fase de la violencia (1946-1953). Bogotá: Universidad de los Andes, Facultad de Ciencias Sociales, Ediciones Uniandes.

Sims, R. L. (1998). La casa grande de Álvaro Cepeda Samudio: novela, historia y multiplicidad de voces. En: Huellas, Revista de la Universidad del Norte, No. 51, 52, 53, diciembre de 1997, abril-agosto de 1998. p.p. $73-85$.

Tirado Mejía, A. (2014). Los años sesenta, una revolución en la cultura. Bogotá: Colección Debate, Penguin Random House Grupo Editorial, S.A.S.

Urdinola Uribe, A. (2004). Faulkner en siete obras del Boom. Cali: Universidad del Valle.

Vergara Aguirre, A. (2001). Coordenadas para un plano de La casa grande de Álvaro Cepeda Samudio, en: Estudios de literatura colombiana, no. 8, enero-junio de 2001.

Recibido: abril 2016/Aprobado: mayo 2016 